\title{
Apical Ballooning Syndrome: Recent Insights from a Consecutive Series of 104 Patients
}

\author{
Sandhya Shresthra1, Daniel Juneau², Daniel Hermann², Gretchen L. Wells² ${ }^{*}$ \\ ${ }^{1}$ Section on Pulmonary/Critical Care Medicine, Department of Internal Medicine, Wake Forest School of \\ Medicine, Winston-Salem, USA \\ ${ }^{2}$ Section on Cardiovascular Medicine, Department of Internal Medicine, Wake Forest School of Medicine, \\ Winston-Salem, USA \\ Email: "gwells@wakehealth.edu
}

Received 26 August 2014; revised 30 October 2014; accepted 10 November 2014

Copyright (C) 2015 by authors and Scientific Research Publishing Inc.

This work is licensed under the Creative Commons Attribution International License (CC BY). http://creativecommons.org/licenses/by/4.0/

(c) (i) Open Access

\begin{abstract}
Apical ballooning syndrome (Takotsubo cardiomyopathy) is an increasingly recognized form of acute systolic dysfunction which is usually reversible. It typically occurs in post-menopausal women following a major psychological stressor. We conducted a single center, retrospective analysis of all hospitalized patients from 2001-2012 and found 104 patients who met the diagnostic criteria for apical ballooning. In this current largest series of its kind, $83 \%$ of the patients were women. Among both men and women, an antecedent stressor was not always identified. The exact pathophysiologic mechanism resulting in apical ballooning remains poorly understood. These findings challenge the paradigm that catecholamine cardiotoxicity in the setting of relative estrogen deficiency results in the cardiomyopathy.
\end{abstract}

\section{Keywords}

Apical Ballooning, Takotsubo, Catecholamines, Estrogen

\section{Introduction}

Apical ballooning syndrome (a.k.a. Takotsubo cardiomyopathy, stress cardiomyopathy or "broken heart syndrome") is an increasingly recognized form of acute reversible left ventricular systolic dysfunction typically involving the apex and mid ventricular segments of the left ventricle and hyperkinesis of the basal segments. Its

"Corresponding author. 
clinical presentation mimics an acute myocardial infarction with regards to symptoms, electrocardiographic changes and abnormal cardiac biomarkers; however, coronary angiography demonstrates no significant coronary stenosis or spasm [1]. The left ventricular function usually normalizes within 3 weeks [2]. The pathophysiology resulting in apical ballooning is incompletely understood. Epidemiologic studies describe 2 striking features which may suggest mechanisms [3]: its occurrence following catastrophic emotional or physical stress and the fact that most patients are elderly women (i.e. postmenopausal).

Elevated serum catecholamine levels were described in 19 patients with apical ballooning [4]. In addition, apical ballooning has been described in patients after intravenous administration of catecholamines and beta receptor agonists [5] as well as iatrogenic administration. However, this conclusion may be open for alternate interpretation as the majority of patients who receive these medications do not develop apical ballooning. As the overwhelming majority of these patients are postmenopausal women, one would speculate that relative estrogen deficiency may be contributory. However, in the one study of apical ballooning where the estrogen levels were measured during the acute event, the concentrations were elevated compared with women with acute myocardial infarction (MI) or with normal coronary arteries leading the authors to speculate that the higher estrogen concentrations may have exerted atheroprotective effects and diverted the stress response to apical ballooning rather than acute myocardial infarction [6]. These varied conclusions should give rise to alternate explanations of the pathophysiology which remains incompletely understood. To investigate other possible associations, we conducted a retrospective review of all hospitalized patients with apical ballooning syndrome as their primary diagnosis over a 10-year period at a tertiary-level academic medical center. To date, our series is the largest of its type reported in the literature.

\section{Materials and Methods}

The Wake Forest Baptist Medical Center patient billing database was queried for the ICD-9 429.83 code (Takotsubo syndrome) as the primary diagnosis at discharge from 2001-2012. There were 130 individuals identified. Of those patients within the database with the appropriate ICD-9 code, each underwent chart review. The review also included independent review of echocardiography and cardiac catheterization images. One hundred four individuals meeting all diagnostic criteria for apical ballooning [2] were included in the final analysis. These criteria included: transient akinesis or dyskinesis of the left ventricular apical and midventricular segments, absence of obstructive coronary artery disease, new electrocardiographic abnormalities, and absence of recent severe head trauma, intracranial bleeding, pheochromocytoma, myocarditis and hypertrophic cardiomyopathy. The Institutional Review Board of Wake Forest Baptist Health approved the study protocol.

Statistical analyses were conducted using SPSS 19.0 (IBM SPSS Statistics, IBM Corporation, Armonk, NY). Baseline characteristics of female subjects compared with male subjects were analyzed with the chi-square and Fisher's exact tests for categorical variables. The Student's t test was used for normally distributed variables and the Mann-Whitney U test was used for variables not normally distributed. Normality was assessed by graphical methods. Values of $<0.05$ were considered significant.

\section{Results}

There were 130 individuals identified. Following chart review, including review of echocardiography and cardiac catheterization images, 104 individuals were included in the final analysis meeting the diagnostic criteria for apical ballooning [2]. The mean age was 64 years, and 86 patients (82.7\%) were women (Table 1$)$. Patient ethnicity consisted of 89 Caucasian, 12 African American, 2 Latino and 1 Asian. The majority of men had a major physical stress as the inciting event (66.7\%); although among the women, there were an equal number of physical and emotional stressors (32.6\% each) as the precipitating event. Interestingly, in both men and women, there were a large number of individuals in which a precipitating stressful event could not be identified (34.9\% of women and $27.8 \%$ of men).

Of the patients, 64 had hypertension and 23 were diabetic, which is the expected prevalence for each in this age group; 23 women (24.4\%) and 5 men (27.8\%) were taking a beta blocker at the time of presentation. Among the women, 6 (7.3\%) were taking hormone replacement therapy (either conjugated estrogens tablets or conjugated estrogens/medroxyprogesterone acetate tablets.

All patients underwent echocardiography at the time of admission; all but 1 had apical ballooning and 1 patient had mid ventricular ballooning. Basal ballooning was not present in our series. No patients had severe 
(>70\%) coronary stenosis on coronary angiography.

There were 3 (2.9\%) deaths which occurred while hospitalized in 2 women and 1 man. The cause of death was arrhythmia in all of the patients. Atrial and ventricular arrhythmias were present in 15 women (17.4\%) and 4 men (22.2\%). The average corrected QT interval was $511.61 \mathrm{msec}$ in men and $493.2 \mathrm{msec}$ in women (Table 2).

\section{Discussion}

This large-case series highlights several important observations. First, a substantial number of individuals in our series did not have an inciting physical or emotional stressor. Case reports and observational studies suggest that the transient stress-induced cardiomyopathy is secondary to a catecholamine surge triggered by emotional or physical stress [3]. Plasma catecholamine levels in patients with apical ballooning are markedly elevated compared with patients with myocardial infarction and pulmonary edema [4]. However, elevated catecholamine levels are not uniformly found in patients with this syndrome suggesting that mechanisms other than catecholamine toxicity may be responsible.

\begin{tabular}{|c|c|c|c|}
\hline & Females & Males & $\mathrm{p}$-value \\
\hline Patients & 86 (82.7\%) & 18 (17.3\%) & \\
\hline Age (mean \pm SD) & $65.45 \pm 11.8$ & $64.83 \pm 12.53$ & 0.902 \\
\hline Ethnicity & & & 0.198 \\
\hline White & 75 (87.2\%) & $14(77.8 \%)$ & \\
\hline African-American & $9(10.3 \%)$ & 3 (16.7\%) & \\
\hline Latino & $2(2.3 \%)$ & $0(0)$ & \\
\hline Asian & $0(0)$ & $1(5.6 \%)$ & \\
\hline
\end{tabular}

Recent Stress

$\begin{array}{lccc}\text { Physical } & 28(32.6 \%) & 12(66.7 \%) & \\ \text { Emotional } & 28(32.6 \%) & 1(5.6 \%) & \\ \text { No stress noted } & 30(34.9 \%) & 5(27.8 \%) & \\ \text { Co-morbidity } & & & \\ \text { Hypertension } & 50(59.9 \%) & 14(77.8 \%) & 0.146 \\ \text { Diabetes } & 19(22.6 \%) & 4(22.2 \%) & 1.000 \\ \text { Depression } & 22(26.2 \%) & 2(11.1 \%) & 0.229 \\ \text { Anxiety } & 22(26.2) & 3(16.7) & 0.550\end{array}$

Table 2. Cardiovascular characteristics of patients with apical ballooning.

\begin{tabular}{cccc}
\hline & Females & Males & p-value \\
\hline $\begin{array}{c}\text { Ejection fraction }(\mathrm{EF}) \\
(\text { mean } \pm \text { SD) }\end{array}$ & $31.22 \pm 13.42$ & $34.06 \pm 11.44$ & 0.406 \\
$\begin{array}{l}\text { QTc interval } \\
\text { (mean } \pm \text { SD) }\end{array}$ & $493.20 \pm 83.54$ & $511.61 \pm 88.37$ & 0.402 \\
\hline
\end{tabular}

* Laboratory values in median, Interquartile range (IQR). 
The mechanism by which epinephrine can induce transient left ventricular (LV) dysfunction remains elusive. The most plausible explanation is a direct toxic effect of catecholamines on cardiac myocytes. Catecholamines decrease myocyte viability through cyclic adenosine monophosphate-mediated calcium overload, resulting in contraction band necrosis, a histologic pattern of myocyte injury observed in apical ballooning which is different from the pattern observed in ischemic cardiac necrosis [4].

${ }^{123}$ I-metaiodobenzyl-guanidine (a norepinephrine analog) imaging in patients with apical ballooning reveals impaired sympathetic innervation in the dysfunctional apex, despite normal perfusion [7]. Case reports of apical ballooning due to intravenous catecholamines routinely used in clinical practice [5] as well as that resulting from iatrogenic administration [8], catecholamine-secreting tumors and acute brain injury [9] also support the notion of acute sympathetically mediated myocardial stunning. Animal studies have demonstrated apical ballooning following administration of catecholamines [10]. In rodent models, myocardial injury was prevented by treatment with alpha and beta adrenergic receptor antagonists [11]. However, in our series, 25 patients were on standard doses of beta blockers at the time of their apical ballooning and their course was not different from the other patients in our series.

An in vivo rat model of Takotsubo cardiomyopathy found that high-dose epinephrine activated a switch of $\beta 2$-adrenergic receptor (B2AR) coupling from the positively inotropic Gs-cAMP to a negatively inotropic Gi signaling pathway. Norepinephrine, which does not activate this Gs/Gi switch, did not precipitate apical ballooning. High dose epinephrine, however, did result in this switch. Prevention of the switch increased sudden death in this model, which is consistent with the protective anti-arrhythmic and anti-apoptotic nature of Gi signaling. This model suggests that an epinephrine-induced B2-AR Gs/Gi switch is responsible for the acute apical dysfunction in Takotsubo cardiomyopathy, but that it may also confer an element of protection against damage by high catecholamines [12].

Another finding in this series comparable to other reports of apical ballooning is the preponderance (80\%) of postmenopausal women with this presentation. Estrogen plays a critical role in protecting the myocardium, possibly by downregulating beta-adrenergic receptors [13]. Postmenopausal women who do not receive estrogen replacement therapy may lose this protection and be more vulnerable to a stress-associated catecholamine surge. However, Brenner et al. (2012) found elevated estrogen concentrations in postmenopausal apical ballooning patients compared with women with acute MI or with normal coronary arteries, leading the authors of this study to speculate that the higher estrogen concentrations might have exerted atheroprotective effects and, thus, diverted the stress response to stress cardiomyopathy rather than myocardial infarction [6].

Interestingly, our series found that 18/104 (17\%) patients were men. These men were the same age as the women at the time of presentation (64 years), unlike acute coronary syndrome where women are on average 7 to 9 years older than men. Most of the men in our series reported physical stress as the inciting event. It remains unclear whether underdiagnosis or misdiagnosis may contribute to the lower prevalence of apical ballooning in men as it may not be suspected in this group. Another potential explanation for fewer men is that sudden cardiac death is much higher among men in this age group than women. It is possible that these men with apical ballooning die before presenting to medical attention [14].

A limitation of our series is that catecholamines were not measured in patients. However, all patients were queried regarding recent stressors and approximately 1/3 could not cite a stressor. If the elevation in catecholamines is caused by an identifiable stressor (or another apparent process such as a pheochromocytoma or CNS trauma) then one could extrapolate that the catecholamines were not elevated in that group of patients. This observation suggests that, while catecholamine excess may contribute to apical ballooning in some cases, it is not the sole cause. Moreover, we have observed that in situations of iatrogenic catecholamine excess, not all patients develop apical ballooning, suggesting that catecholamine excess may be contributory but not sufficient to result in this syndrome.

\section{Conclusion}

In this largest series of its kind, apical ballooning syndrome was primarily identified in older women, providing further speculation that relative estrogen deficiency may play an important role in its development. While the pathophysiology remains elusive, many individuals have an inciting stressor leading to the hypothesis that catecholamine excess is critical to its development. However, in our series, approximately $1 / 3$ of individuals did not have an inciting stressor, leading us to believe that other pathways may result in apical ballooning. Further research is needed in this exciting and rapidly evolving area of cardiology. 


\section{Acknowledgements}

The authors gratefully acknowledge the editorial support of Amanda Burnette, Trilbia Cline and Karen Klein.

\section{References}

[1] Tsuchihashi, K., Ueshima, K., Uchida, T., Oh-mura, N., Kimura, K., Owa, M., et al. (2001) Transient Left Ventricular Apical Ballooning without Coronary Artery Stenosis: A Novel Heart Syndrome Mimicking Acute Myocardial Infarction. Journal of the American College of Cardiology, 38, 11-18. http://dx.doi.org/10.1016/S0735-1097(01)01316-X

[2] Prasad, A. (2007) Apical Ballooning Syndrome: An Important Differential Diagnosis of Acute Myocardial Infarction. Circulation, 115, e56-e59. http://dx.doi.org/10.1161/CIRCULATIONAHA.106.669341

[3] Akashi, Y.J., Goldstein, D.S., Barbaro, G. and Ueyama, T. (2008) Takotsubo Cardiomyopathy: A New Form of Acute, Reversible Heart Failure. Circulation, 118, 2754-2762. http://dx.doi.org/10.1161/CIRCULATIONAHA.108.767012

[4] Wittstein, I.S., Thiemann, D.R., Lima, J.A., Baughman, K.L., Schulman, S.P., Gerstenblith, G., et al. (2005) Neurohumoral Features of Myocardial Stunning Due to Sudden Emotional Stress. The New England Journal of Medicine, 352, 539-548. http://dx.doi.org/10.1056/NEJMoa043046

[5] Abraham, J., Mudd, J.O., Kapur, N., Klein, K., Champion, H.C. and Wittstein, I.S. (2009) Stress Cardiomyopathy after Intravenous Administration of Catecholamines and Beta-Receptor Agonists. Journal of the American College of Cardiology, 53, 1320-1325. http://dx.doi.org/10.1016/j.jacc.2009.02.020

[6] Brenner, R., Weilenmann, D., Maeder, M.T., Jorg, L., Bluzaite, I., Rickli, H., et al. (2012) Clinical Characteristics, Sex Hormones, and Long-Term Follow-Up in Swiss Postmenopausal Women Presenting with Takotsubo Cardiomyopathy. Clinical Cardiology, 35, 340-347. http://dx.doi.org/10.1002/clc.21986

[7] Burgdorf, C., von Hof, K., Schunkert, H. and Kurowski, V. (2008) Regional Alterations in Myocardial Sympathetic Innervation in Patients with Transient Left-Ventricular Apical Ballooning (Tako-Tsubo Cardiomyopathy). Journal of Nuclear Cardiology, 15, 65-72. http://dx.doi.org/10.1016/j.nuclcard.2007.08.005

[8] Litvinov, I.V., Kotowycz, M. and Wassmann, S. (2009) Iatrongenic Epinephrine-Induced Reverse Takotsubo Cardiomyopathy: Direct Evidence Supporting the Role of Catecholamines in the Pathophysiology of the "Broken Heart Syndrome”. Clinical Research in Cardiology, 98, 457-462. http://dx.doi.org/10.1007/s00392-009-0028-y

[9] Lee, V.H., Oh, J.K., Mulvagh, S.L. and Wijdicks, E.F.M. (2006) Mechanisms in Neurogenic Stress Cardiomyopathy after Aneurysmal Subarachnoid Hemorrhage. Neurocritical Care, 5, 243-249. http://dx.doi.org/10.1385/NCC:5:3:243

[10] Ueyama, T. (2004) Emotional Stress-Induced Tako-Tsubo Cardiomyopathy: Animal Model and Molecular Mechanism. Annals of the New York Academy of Sciences, 1018, 437-444. http://dx.doi.org/10.1196/annals.1296.054

[11] Ueyama, T., Kasamatsu, K., Hano, T., Yamamoto, K., Tsuruo, Y. and Nishio, I. (2002) Emotional Stress Induces Transient Left Ventricular Hypocontraction in the Rat via Activation of Cardiac Adrenoceptors: A Possible Animal Model of "Tako-Tsubo" Cardiomyopathy. Circulation Journal, 66, 712-713. http://dx.doi.org/10.1253/circj.66.712

[12] Paur, H., Wright, P.T., Sikkel, M.B., Tranter, M.H., Mansfield, C., O’Gara, P., et al. (2012) High Levels of Circulating Epinephrine Trigger Apical Cardiodepression in a Beta ${ }_{2}$-Adrenergic Receptor/ $\mathrm{G}_{\mathrm{i}}$-Dependent Manner: A New Model of Takotsubo Cardiomyopathy. Circulation, 126, 697-706. http://dx.doi.org/10.1161/CIRCULATIONAHA.112.111591

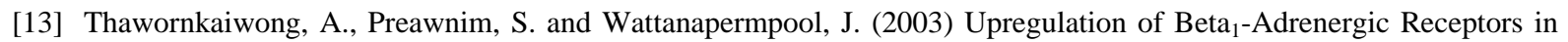
Ovariectomized Rat Hearts. Life Sciences, 72, 1813-1824. http://dx.doi.org/10.1016/S0024-3205(02)02473-6

[14] Schneider, B., Athanasiadis, A. and Sechtem, U. (2013) Gender-Related Differences in Takotsubo Cardiomyopathy. Heart Failure Clinics, 9, 137-146. http://dx.doi.org/10.1016/j.hfc.2012.12.005 
Scientific Research Publishing (SCIRP) is one of the largest Open Access journal publishers. It is currently publishing more than 200 open access, online, peer-reviewed journals covering a wide range of academic disciplines. SCIRP serves the worldwide academic communities and contributes to the progress and application of science with its publication.

Other selected journals from SCIRP are listed as below. Submit your manuscript to us via either submit@scirp.org or Online Submission Portal.
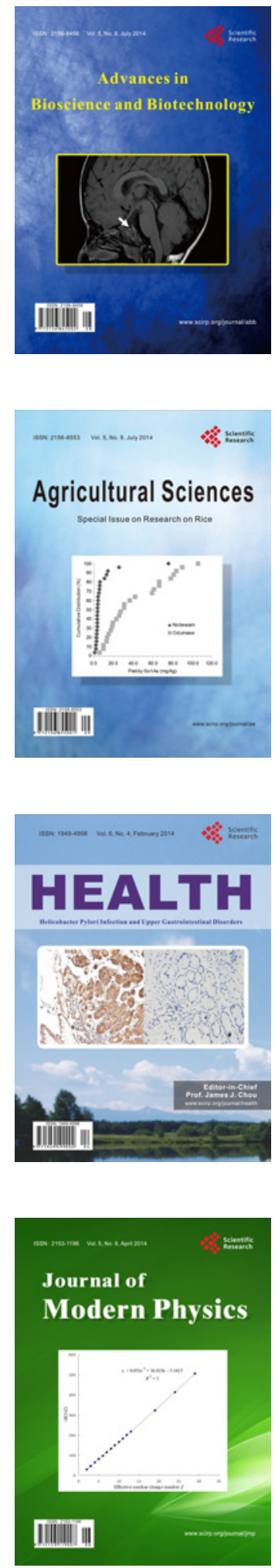
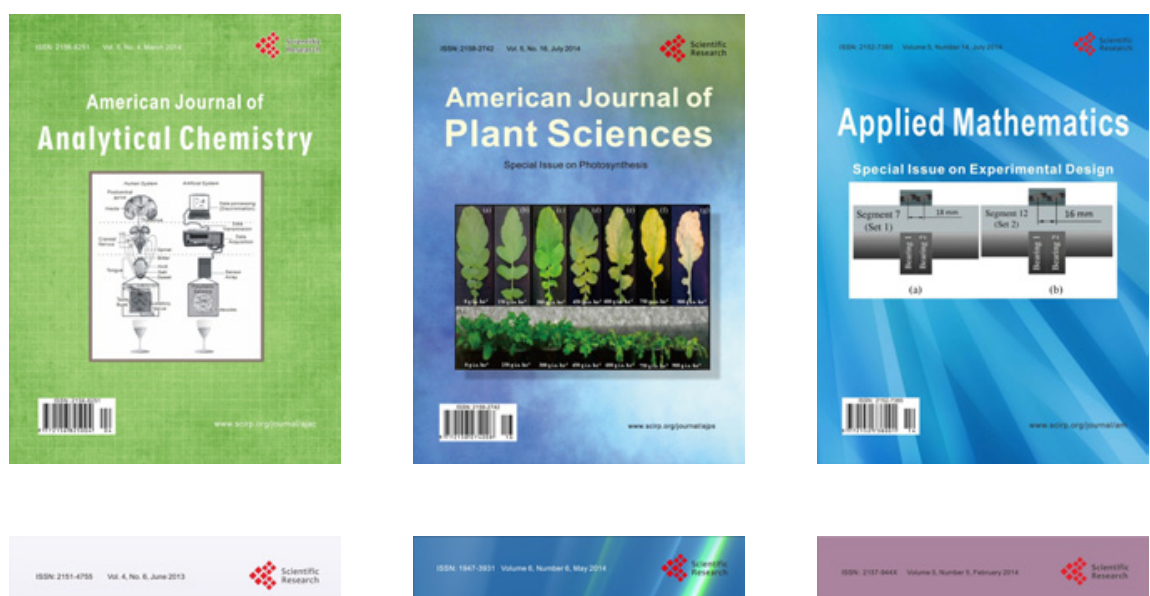

Creative Education
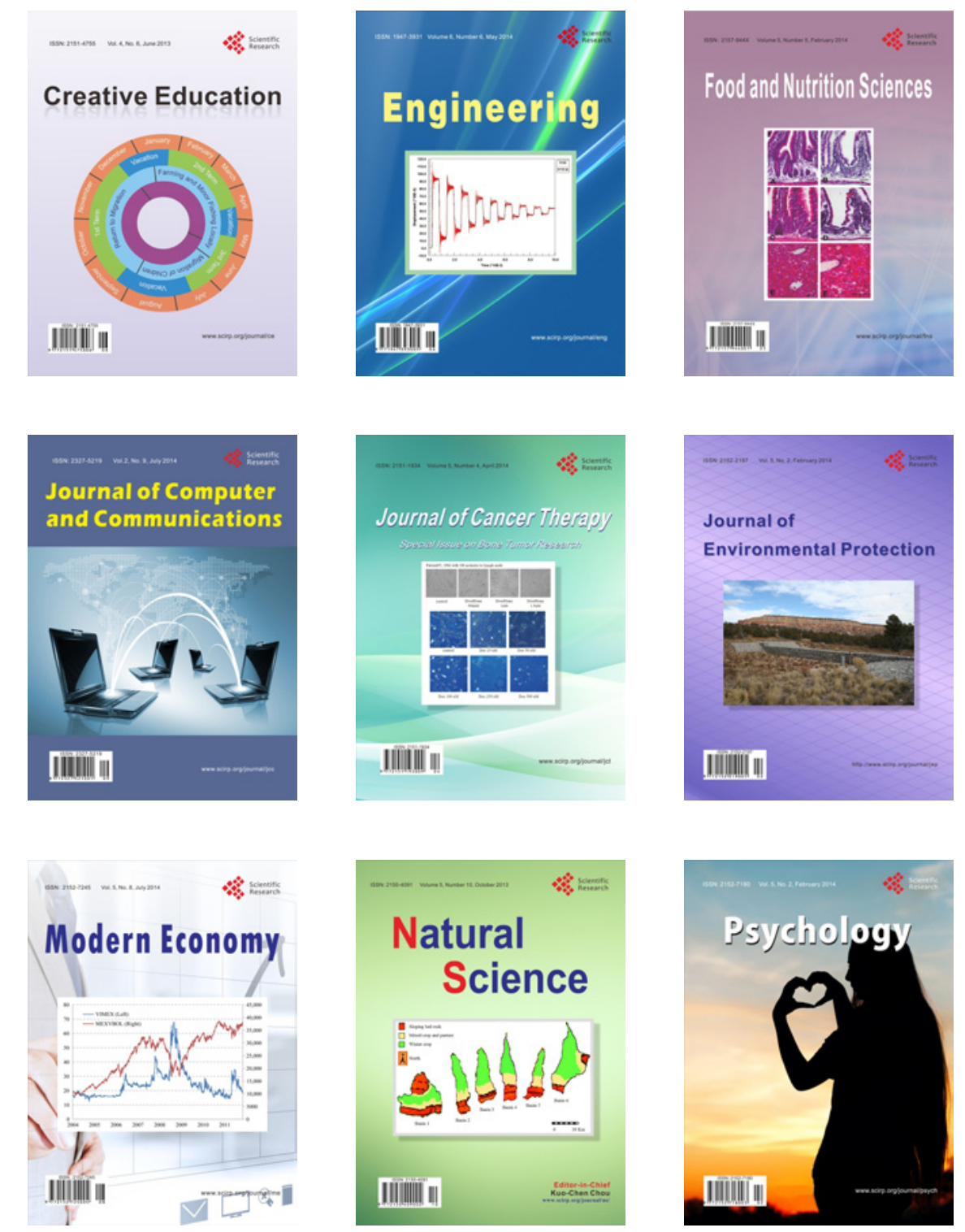